\title{
Effects of Shadowing and Tracking on Intermediate EFL Learners' Oral Fluency
}

\section{Fereshteh Yavari}

Department of English, Isfahan (Khorasgan) Branch, Islamic Azad University, Isfahan, Iran,fereshtehy48@gmail.com

\section{Sajad Shafiee}

Asst. Proft, Department of English, Shahrekord Branch, Islamic Azad University, Shahrekord, Iran, s.shafiee@iaushk.ac.ir

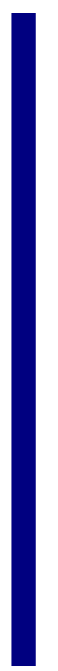

\begin{abstract}
The present study attempted to explore the effects of employing shadowing and tracking on Iranian EFL learners' speaking fluency. From among 112 intermediate Iranian EFL learners at Jahad Danesheshgahi Language Institute in Isfahan, Iran, 60 were selected in the wake of administering the Preliminary English Test and divided into four groups: shadowing group (SG), tracking group (TG), shadowing and tracking group (STG), and control group (CG). The data elicitation techniques employed as the pre-test and post-test were semi-structured interviews in which learners answered several questions. Fluency scores were derived out of the formula suggested by Yuan and Ellis (2003). One-way between-groups ANOVA and paired samples $t$ test were used to make between-groups and within-group comparisons and to discern whether the participants in each group could gain an advantage from their specific methods of instruction. The analysis of the obtained data via SPSS indicated that (a) the successful performance of the participants in the experimental groups was shown to be attributable to using shadowing and tracking techniques as tools for improving oral fluency, and that (b) among these experimental groups, STG was shown to be significantly better than the SG, which in turn was significantly better than TG.
\end{abstract}

Keywords: shadowing, tracking, oral fluency, EFL learners, speaking, learning

\section{INTRODUCTION}

Languages consist of four main skills: speaking, reading, writing and listening. Speaking is the ability to combine words together and create sentences to convey messages, thoughts, and ideas. In today's world, speaking the international language of English is very important for human interaction since many people in different corners of the world speak through English. In this global era, many people use English as a medium of

Citation: Yavari, F., \& Shafiee, S. (2019). Effects of Shadowing and Tracking on Intermediate EFL Learners' Oral Fluency. International Journal of Instruction, 12(1), 869-884. https://doi.org/10.29333/iji.2019.12156a 
communication and it makes people who come from different countries communicate more easily (Efrizal, 2012).

There are many factors affecting speaking proficiency. All of these factors (e.g. lexical knowledge, accuracy, intonation and accent, fluency, and pronunciation, just to name a few) play a significant role in building one's speaking skills. The focus of the present study was on English oral fluency as an effective factor in speaking. Fluency is regarded as performance that is based on chunks which function as units and are retrieved as wholes (Skehan, 2003). Poor fluency can limit the interaction patterns and may affect the satisfaction of speakers and interlocutors because they practice the language in realtime (Kasap, 2005).

Many researchers examined effective methods of teaching a second or foreign language and focused on topics such as roles of grammar, materials, and technology in teaching or developing fluency, teaching productive or receptive abilities, and motivating learners (Kalanzade, Mirchenari, \& Bakhtiarvand, 2013). Iranian English teachers tend to use different methods to facilitate learning the speaking skill in the classroom, but some utilize methodologies which mostly lead to failure (Rahimy \& Safapour, 2012). Yet, there are many more techniques worthy of being tested and investigated; two such techniques are shadowing and tracking. Shadowing refers to the act or task of listening in which the learners track the heard speech and repeat it as exactly as possible (Mochizuki, 2006), and tracking refers to the practice of listening and speaking in which students speak along with videos in the target language (Willardson, 2014). The present study was primarily aimed at investigating the effectiveness of shadowing and tracking in improving the oral fluency of intermediate Iranian EFL learners.

\section{LITERATURE REVIEW}

According to Chany (1998), speaking is the activity of constructing and sharing meaning through the use of verbal and non-verbal signs in a variety of contexts. The importance of speaking in language learning and teaching is obvious. For many years, students recited and memorized the dialogs but today, they should learn how to present themselves and follow social and cultural rules in any situation. They can learn to speak in various communicative situations. Public speaking plays an important role from recruitment to persuasion, from informing to initiation. Hence, because of the importance of speech, learning speaking can be effective and can lead to more successful results for any individual, group, or organization. There are a few basics one must first understand such as different types of speeches and when to use them, the unity of speech, and how to reduce anxiety and increase confidence in public speaking (Ricketts \& Keith, 2013). Fluency, which is a key element in speaking, is also presented as a challenge for language learners and teachers. This is also confirmed by researchers such as Hunter (2011) who claimed that a major issue that continues to challenge language teachers is how to ensure that learners develop accuracy and complexity in their speaking as well as fluency because teachers know that too much corrective feedback can make learners reluctant to speak, while not enough may allow their errors to become entrenched. Ellis (1994) proposed that challenges which learners encounter in fluency and accuracy because of the psycholinguistic processes involved in using L2 
knowledge are distinct from acquiring new knowledge. To improve one's fluency and accuracy, the learner must attend consciously to the input and, perhaps also, make efforts to monitor output, but doing so may interfere with fluent reception and production (Housen \& Kuiken, 2009).

Spoken language production by EFL learners is often considered fundamental to communication and one of the most difficult aspects and major challenges of language learning (Al Hosni, 2014; Brown \& Yule, 1983; Riyaz \& Mullick, 2016; Pathan, Aldersi, \& Alsout, 2014) because it is held back by many factors (Al-Jamal, 2014; Pathan, et al., 2014). In reality, many language learners find it difficult to express themselves in spoken language in the target language. Each student has his/her own problems. As Nunan (1991, p. 39) stated, "success is measured in terms of the ability to carry out a conversation in the target language." So, students could get de-motivated and have no interest if they do not use speaking strategies to practice speaking fluency in the classroom. However, if students are given enough chances to practice speaking using the right strategies, they will be interested and motivated. One of these strategies is using shadowing and tracking to improve oral performance.

Tateuchi explained that early research into shadowing was carried out in the field of psychology in the 60s (as cited in Mochizuki, 2006). It was used to train interpreters and continues to be used for that purpose. Tanaka (2002) listed shadowing as one of 13 techniques used for interpreter training, stating that shadowing is effective in developing a good ear for language, specifically in regard to accent and intonation, as well as improving overall listening ability. Having been seen to be effective in improving the listening ability of interpreters, shadowing started to be used in the wider context of ELT in Japan. Using shadowing in ELT was a response to the need to improve students' listening skills at a time when, in comparison to reading, writing, and speaking, listening methodology was underdeveloped (Tamai, 2005).

On the other hand, in tracking, a student is asked to repeat after the teacher/audio/video, one phrase at a time (Beebe, Pearson, \& Koch, 1984). This technique as practiced at the Beebs Speech and Hearing Center (Easton, PA) was first a technique developed for hearing-impaired children. Later adaptations and uses of tracking entailed its being employed in language learning/teaching contexts for the purposes of listening/speaking.

Azimi and Ghanbari (2012) introduced the effect of conversational shadowing on enhancing the level of accuracy of EFL learners during their oral performance. Participants in this study consisted of 60 students studying English in an English institute at intermediate level in Tehran as an EFL context. The participants received conversational shadowing practice during their interaction with the instructor and peers. A general English proficiency test, pre-test and post-test of simple past tense were administered to them. Two intact classes were selected as control group and experimental group in this study. The experimental group was taught simple past tense based on conversational shadowing while the control group was taught as it had been demonstrated in their books. The result of quantitative and qualitative studies, when integrated, supported this assumption by showing that oral repetition served as a scaffolding device that helped learners use correct form of simple past tense. Shadowing 
was not perceived as enjoyable or useful in itself, but a few highly proficient students, who had utilized the pertinent technique in the service of more interesting activities, acknowledged that they had learned useful sentences and make fewer errors during their conversation. Therefore, conversational shadowing can be best utilized to help intermediate EFL students to perfect their correct use of grammar when they are interacting with their peers.

Zakeri (2014) discovered that there is a link between shadowing and the fluency of EFL learners' oral performance. Forty learners of intermediate level took part in the study for a month as part of either an experimental or control group. A strong relationship between shadowing and the fluency of learners' L2 production was found.

Willardson (2014) investigated the effectiveness of computer-enhanced shadowing and tracking pronunciation exercises for intermediate level foreign language learners. The participants were a group of high school students that were members of a fourth-year French class. As part of their regular class time, the students participated in two types of exercises, in-class group work and computer-lab self-directed exercises, in which the students watched videos with subtitles while repeating what they heard. Satisfaction with the program was determined by collecting feedback from the students using qualitative and quantitative surveys. The students found videos interesting and appreciated the learning autonomy provided by the self-directed exercises. Improvement was assessed by comparing performance on pre-and post-tests measuring both free response and reading pronunciation. Significant improvements were observed in both categories, but the improvements in reading pronunciation were most striking.

Many studies have highlighted the effective role of using shadowing and tracking techniques in the process of speaking development. Shadowing has also been used as a technique for training simultaneous interpreters (Tanaka, 2002). The idea behind trainees performing shadowing tasks is that one must become able to listen and speak simultaneously in the L1 before moving on to simultaneous cross-language listening and speaking. The connected discourse tracking procedure developed by De Filippo and Scott (1978) has been utilized as a training and evaluation technique that approximates aspects of everyday communication.

As L2 speaking has a crucial role in success of English learning, the aim of this study was finding out whether shadowing and tracking techniques used for teaching English could have any effects on oral fluency of intermediate Iranian EFL learners, and if so, which one proved to be more effective than the other. As such the following research questions were proposed:

1. Does shadowing have any effects on speaking fluency of intermediate Iranian EFL learners?

2. Does tracking have any effects on speaking fluency of intermediate Iranian EFL learners?

3. Do shadowing and tracking have any effects on speaking fluency of intermediate Iranian EFL learners? 
4. Are there any differences in speaking fluency of the learners exposed to shadowing and tracking to those who were not?

\section{METHOD}

\section{Participants}

To choose the participants for this research, intermediate EFL learners from Jahad Daneshgahi language institute in Isfahan were asked to take part in the study. Preliminary English Test (PET) was utilized to render a homogeneous sample from among 112 intermediate EFL at the institute. Those whose PET scores were within one standard deviation above and below the mean were chosen to take part in this study. The selected sample consisted of 60 female native speakers of Persian with an age range of 15 to 20 . After explaining the aims of the study to the participants and testing them by PET, the researcher randomly chose one of the groups to be the control group (CG) and the three others as the experimental groups, i.e., shadowing group (SG), tracking group (TG), and shadowing and tracking group (STG).

\section{Materials and Instruments}

The book which was used in this study was Speak Now 1 intended for intermediate learners and had 32 units accompanied by 8 videos. These videos covered different subjects such as friends and family, restaurant, health, jobs, free time, travel, style and fashion, and opinion. The time of each video was about 10 minutes and in each session one of these videos was selected and displayed for students. Three types of instruments, including pre-test of fluency, post-test, and PET were used in this study.

PET is a preliminary English test examination provided by Cambridge English Language Assessment and it is valuable for work, study, travel and international business. It helps to assess language skills and practical abilities. PET consists of three sections: reading and writing, listening and speaking.

The pre-test and post-test in this study took the form of interviews employed to measure learners' fluency and gather the required data. Each of these tests comprised oral questions related to the topics such as historical building in Isfahan and favorite places for vacations, and the learners were expected to answer these questions in a fluent way. The questions were the same for all the learners. The inter-rater reliability indexes of the fluency scores obtained on the pre-test and post-test were calculated through Pearson correlation formula, and the pre-test reliability index equaled .79 while that of the posttest equaled .81 .

Among the different measures of fluency, the following was used to evaluate the fluency of oral productions of the participants. Then the researcher and her co-rater scored their ability in fluency according to the number of syllables produced per minute of speech. This measure of fluency has been widely used in L2 acquisition studies (e.g., Sabzevari, 2012; Yuan \& Ellis, 2003, to name just a few). 


\section{Procedures}

Prior to the treatment, 112 female students from Jahad Daneshgahi language school took PET and 60 of them, who obtained scores between one standard deviation above and below the mean, were chosen to participate in this study. Then the participants were randomly divided into four groups and were exposed to different instructional procedures: playing video by using shadowing technique for one of the experimental groups, playing video by using tracking technique for the other experimental group, and playing video by using shadowing and tracking for the last experimental group. However, no techniques of shadowing and tracking were used for the control group learners. The treatment was performed during 10 sessions, two sessions per week. The 15-minute-per-session treatment was administered as part of the regular class hours, which took an hour and thirty minutes. Semi-structured interviews about topics such as historical buildings in Isfahan and favorite places for vacation were administered as the pre-test. After the completion of the treatment sessions, in the post-test stage of the study, the semi-structured interview on the same topics used for the pre-test was employed to estimate the fluency scores of the participants. Finally, the fluency scores of the participants were gauged and the scores were prepared for statistical analysis.

\section{FINDINGS}

As it was mentioned above, the participants in this study were divided into four groups of equal size: Shadowing group (SG), Tracking group (TG), Shadowing and Tracking group (STG), and Control group (CG). All the subjects in different groups took part in an interview pre-test, and their fluency scores were gauged. The experimental groups received their relevant treatments, while the control group received neither shadowing nor tracking. The four groups once again sat for an interview test after the implementation of the experiment. The data obtained were analyzed using the SPSS: paired-sample $t$ test was used to examine the possible improvements from pre-test to post-test for research question 1,2 and 3. One-way between groups ANOVA was conducted to find an answer to the forth research question of the study.

\section{Results for the First Research Question}

The first research question of the study asked whether shadowing have any effect on speaking fluency of intermediate Iranian EFL learners or not. To find an answer to this research question, the fluency pre-test scores of the participants in the SG were compared with their fluency post-test scores. This enable the researchers to find out whether the possible differences between the fluency pre-test and fluency post-test scores were statistically significant or not, and thus understand whether the improvements were considerable or not. Table 1 presents the descriptive statistics for the fluency pre-test and fluency post-test scores of the SG. 
Table 1

Descriptive statistics results comparing the pre-test and post-test scores of the SG learners

\begin{tabular}{llllll}
\hline & & $\mathrm{N}$ & Mean & Std. Deviation & Std. Error Mean \\
\hline \multirow{2}{*}{ SG } & Pre-test & 15 & 1.55 & .09 & .02 \\
& Post-test & 15 & 2.15 & .11 & .02 \\
\hline
\end{tabular}

The SG learners obtained the mean scores of 1.55 on the pre-test and 2.15 on the posttest. To see if the difference between these two mean scores was statistically significant or not, the researcher had to check the paired-samples $t$ test table below:

Table 2

Paired-Samples t test results comparing the pre-test and post-test scores of the SG learners

\begin{tabular}{|c|c|c|c|c|c|c|c|}
\hline \multirow{3}{*}{ Mean } & & aired Diffe & & & \multirow{3}{*}{$t$} & \multirow{3}{*}{$d f$} & \multirow{3}{*}{$\begin{array}{l}\text { Sig. } \\
\text { (2- } \\
\text { tailed) }\end{array}$} \\
\hline & \multirow{2}{*}{ Std. Deviation } & \multirow{2}{*}{$\begin{array}{l}\text { Std. } \text { Error } \\
\text { Mean }\end{array}$} & \multicolumn{2}{|c|}{$\begin{array}{l}95 \% \text { Confidence Interval of } \\
\text { the Difference }\end{array}$} & & & \\
\hline & & & Lower & Upper & & & \\
\hline-.59 & .03 & .008 & -.61 & -.58 & -68.04 & 14 & .000 \\
\hline
\end{tabular}

The most important piece of information in Table 2 is the $p$ value under the Sig. (2tailed) column. This value should be compared with the significance level (i.e., .05) to see if the difference between the two sets of scores had been statistically significant or not. A $p$ value less than .05 indicates a significant difference between the two sets of scores, and a $p$ value larger than .05 shows a difference which did not reach statistical significance. Since the $p$ value under the Sig. (2-tailed) column in Table 2 was less than the significance level, it could be inferred that the difference between the pre-test $(M=$ $1.55)$ and post-test $(M=2.15)$ scores of the SG learners was statistically significant.

\section{Results for the Second Research Question}

The second research question of the study aimed to find out whether tracking was a useful strategy in order to boost the oral fluency of Iranian EFL learners or not. The results of comparing the pre-test and post-test scores of the tracking group (TG) learners are provided in the following tables:

Table 3

Descriptive statistics results comparing the pre-test and post-test scores of the TG learners

\begin{tabular}{clccll}
\hline & & $N$ & Mean & Std. Deviation & Std. Error Mean \\
\hline \multirow{2}{*}{ TG } & Pre-test & 15 & 1.47 & .17 & .04 \\
& Post-test & 15 & 1.84 & .17 & .04 \\
\hline
\end{tabular}

Table 3 divulges the fact that the TG learners improved from the mean score of 1.47 on the pre-test to the mean score of 1.84 on the post-test. To see if this difference between the pre-test and post-test scores of the TG learners was statistically significant or not, the following table had to be checked: 
Table 4

Paired-Samples $t$ test results comparing the pre-test and post-test scores of the TG learners

\begin{tabular}{|c|c|c|c|c|c|c|c|}
\hline \multirow{3}{*}{ Mean } & & aired Diffe & & & \multirow{3}{*}{$t$} & \multirow{3}{*}{$d f$} & \multirow{3}{*}{$\begin{array}{l}\text { Sig. } \\
\text { (2-tailed) }\end{array}$} \\
\hline & \multirow[t]{2}{*}{ Std. Deviation } & \multirow{2}{*}{$\begin{array}{l}\text { Std. Error } \\
\text { Mean }\end{array}$} & \multicolumn{2}{|c|}{$\begin{array}{l}\text { 95\% Confidence Interval of } \\
\text { the Difference }\end{array}$} & & & \\
\hline & & & Lower & Upper & & & \\
\hline-.37 & .04 & .01 & -.39 & -.34 & -29.63 & 14 & .000 \\
\hline
\end{tabular}

Results of paired-samples $t$ test in Table 3.4 revealed that there was a statistically significant difference between the pre-test $(M=1.47)$ and post-test $(M=1.84)$ scores of the TG learners.

\section{Results for the Third Research Question}

The penultimate research question of the current study sought to uncover whether shadowing and tracking had a combined effect on the oral fluency of Iranian EFL learners or not. The results of comparing the pre-test and post-test scores of the shadowing-and-tracking group (STG) learners are displayed in Tables 5 and 6:

Table 5

Descriptive statistics results comparing the pre-test and post-test scores of the STG learners

\begin{tabular}{lllcll}
\hline & & $N$ & Mean & Std. Deviation & Std. Error Mean \\
\hline \multirow{2}{*}{ STG } & Pre-test & 15 & 1.56 & .10 & .02 \\
& Post-test & 15 & 2.45 & .12 & .03 \\
\hline
\end{tabular}

Table 5 made it clear that the STG learners' fluency score ameliorated from the mean score of 1.56 on the pre-test to the mean score of 2.45 on the post-test. To find out whether this difference between the pre-test and post-test scores of the STG learners was statistically significant or not, the following table had to be consulted:

Table 6

Paired-Samples $t$ test results comparing the pre-test and post-test scores of the STG learners

\begin{tabular}{|c|c|c|c|c|c|c|c|}
\hline \multirow{3}{*}{ Mean } & \multirow{3}{*}{ Std. Deviation } & \multicolumn{3}{|c|}{ Paired Differences } & \multirow{3}{*}{$\mathrm{t}$} & \multirow{3}{*}{ df } & \multirow{3}{*}{$\begin{array}{l}\text { Sig. } \\
\text { (2-tailed) }\end{array}$} \\
\hline & & \multirow{2}{*}{$\begin{array}{l}\text { Std. Error } \\
\text { Mean }\end{array}$} & \multicolumn{2}{|c|}{$\begin{array}{l}\text { 95\% Confidence Interval of } \\
\text { the Difference }\end{array}$} & & & \\
\hline & & & Lower & Upper & & & \\
\hline-89 & .10 & .02 & $\begin{array}{l}-.94 \\
\end{array}$ & -.83 & -34.42 & 14 & .000 \\
\hline
\end{tabular}

Results obtained from the paired-samples $t$ test in Table 6 indicated that there was a statistically significant difference between the pre-test $(M=1.56)$ and post-test $(M=$ 2.45) scores of the STG learners.

\section{Results for the Fourth Research Question}

The final research question of the study was: Are there any differences in speaking fluency of the learners exposed to shadowing and tracking and those who were not? To come up with the answer to this research question, one-way between groups ANOVA was conducted twice: once for the comparison of the oral fluency scores of the SG, TG, 
STG and CG at the outset of the study and a once again for comparing these four groups' oral fluency scores after the experiment was conducted. What follows is the results of the related analyses.

\section{Pre-test results}

The results of the comparison of the four groups on the pre-test are displayed in Tables 7 and 8 :

Table 7

Descriptive statistics results comparing SG, TG, STG, and CG learners' pre-test scores

\begin{tabular}{lllllll}
\hline & $\mathrm{N}$ & Mean & Std. Deviation & Std. Error & Minimum & Maximum \\
\hline SG & 15 & 1.55 & .09 & .02 & 1.42 & 1.72 \\
\hline TG & 15 & 1.47 & .17 & .04 & 1.13 & 1.76 \\
\hline STG & 15 & 1.56 & .10 & .02 & 1.37 & 1.69 \\
\hline CG & 15 & 1.50 & .11 & .02 & 1.33 & 1.68 \\
\hline Total & 60 & 1.52 & .12 & .01 & 1.13 & 1.76 \\
\hline
\end{tabular}

The mean scores of the SG $(M=1.55)$, TG $(M=1.47)$, STG $(M=1.56)$, and CG $(M=$ $1.50)$ were different from one another on the oral fluency pre-test. To figure out whether the differences among these mean scores were significant or not, one needed to check the $p$ value under the Sig. column in the ANOVA table below:

Table 8

Results of one-way ANOVA for comparing SG, TG, STG, and CG mean scores on the pre-test

\begin{tabular}{llllll}
\hline & Sum of Squares & df & Mean Square & F & Sig. \\
\hline Between Groups & .07 & 3 & .02 & 1.56 & .20 \\
\hline Within Groups & .86 & 56 & .01 & & \\
\hline Total & .93 & 59 & & & \\
\hline
\end{tabular}

As is displayed in Table 8 , there was not a statistically significant difference in the pretest scores for SG $(M=1.55, S D=.09)$, TG $(M=1.47, S D=.17)$, STG $(M=1.56, S D=$ $.10)$, and CG $(M=1.50, S D=.11)$ because the $p$ value under the Sig. column was greater than the specified level of significance (i.e. $.20>.05$ ), indicating that the four groups did not significantly differ prior to the commencement of the experiment. This made the four groups comparable.

\section{Post-test results}

After the instructional period ended, the post-test scores of the learners were obtained and compared through one-way between, the results of which are shown in what follows: 
Table 9

Descriptive statistics results comparing SG, TG, STG, and CG learners' post-test scores

\begin{tabular}{llcccc}
\hline & $\mathrm{N}$ & Mean & Std. Deviation & Std. Error & Maximum \\
\hline SG & 15 & 2.15 & .11 & .02 & 2.36 \\
\hline TG & 15 & 1.84 & .17 & .04 & 2.11 \\
\hline STG & 15 & 2.45 & .12 & .03 & 2.69 \\
\hline CG & 15 & 1.67 & .11 & .002 & 1.85 \\
\hline Total & 60 & 2.03 & .32 & .04 & 2.69 \\
\hline
\end{tabular}

Table 9 shows that the mean scores of the SG $(M=2.15)$, TG $(M=1.84)$, STG $(M=$ $2.45)$, and CG $(M=1.67)$ learners differed from one another on the post-test of oral fluency. In order to find out whether the differences among these mean scores were statistically significant or not, the researcher had to consult the $p$ value in Table 10:

Table 10

Results of one-way ANOVA for comparing SG, TG, STG, and CG mean scores on the post-test

\begin{tabular}{llllll}
\hline & Sum of Squares & df & Mean Square & F & Sig. \\
\hline Between Groups & 5.28 & 3 & 1.76 & 97.92 & .000 \\
\hline Within Groups & 1.00 & 56 & .01 & & \\
\hline Total & 6.28 & 59 & & & \\
\hline
\end{tabular}

It is shown in Table 10 that there was a statistically significant difference in the post-test scores of SG $(M=2.15, S D=.11)$, TG $(M=1.84, S D=.17)$, STG $(M=2.45, S D=$ $.12)$, and CG $(M=1.67, S D=.11)$ learners due to the fact that the $p$ value was found to be smaller than the level of significance (i.e., .000<.05). To see the pair-wise comparisons of these four groups on the post-test, Table 11 had to be checked:

Table 11

Scheffe post hoc test results for comparing SG, TG, STG, and CG mean scores on the post-test

\begin{tabular}{|c|c|c|c|c|c|c|}
\hline \multirow[t]{2}{*}{ Groups } & & \multirow[t]{2}{*}{ Mean Difference } & \multirow[t]{2}{*}{ Std. Error } & \multirow[t]{2}{*}{ Sig. } & \multicolumn{2}{|c|}{ 95\% Confidence Interval } \\
\hline & & & & & Lower Bound & Upper Bound \\
\hline \multirow{3}{*}{ SG } & TG & $.30^{*}$ & .04 & .000 & .16 & .44 \\
\hline & STG & $-.29^{*}$ & .04 & .000 & -.43 & -.15 \\
\hline & CG & $.47^{*}$ & .04 & .000 & .33 & .61 \\
\hline \multirow{3}{*}{ TG } & SG & $-.30^{*}$ & .04 & .000 & -.44 & -.16 \\
\hline & STG & $-.60^{*}$ & .04 & .000 & -.74 & -.46 \\
\hline & CG & $.17^{*}$ & .04 & .010 & .03 & .31 \\
\hline \multirow{3}{*}{ STG } & SG & $.29^{*}$ & .04 & .000 & .15 & .43 \\
\hline & TG & $.60^{*}$ & .04 & .000 & .46 & .74 \\
\hline & CG & $.77^{*}$ & .04 & .000 & .63 & .91 \\
\hline \multirow{3}{*}{ CG } & SG & $-.47^{*}$ & .04 & .000 & -.61 & -.33 \\
\hline & TG & $-.17^{*}$ & .04 & .010 & -.31 & -.03 \\
\hline & STG & $-.77^{*}$ & .04 & .000 & -.91 & -.63 \\
\hline
\end{tabular}

According to the information presented in Table 11, the difference between SG $(M=$ 2.15) and TG $(M=1.84)$ was statistically significant, which means shadowing was 
significantly more effective than tracking. In addition, the difference between SG and STG $(M=2.45)$ reached statistical significance, which shows that the combined effect of shadowing and tracking was significantly more effective than the effect of shadowing alone; this was also the case with tracking. That is, the combined effect of shadowing and tracking was found to be more effective than the effect of tracking alone. Moreover, these three experimental groups managed to have significantly higher mean scores than the control group $(M=1.67)$.

\section{DISCUSSION}

The lack of research about the impacts of using shadowing and tracking techniques on oral fluency of intermediate Iranian EFL learners was felt in the literature and thus this incentive led to carrying out the present study. What can be construed from the findings of this study is that using shadowing and tracking techniques seemed to have positive effects on developing oral fluency. Although there were no significant differences between groups at the beginning of the research, the scores of the experimental groups were higher than those control group in the post-test. These results support the effectiveness of shadowing and tracking techniques. These obtained results are discussed and compared with the relevant previous studies below.

\section{Discussing the First Research Question}

The reason behind the effectiveness of shadowing on speaking fluency of the EFL learners could be related to unique characteristics of this technique for teaching listening. According to Tannen (2007), shadowing responds to a basic human drive to imitate and repeat. Murphey (2001) also stated that, shadowing is "a tool of recursion" because it allows for "repeated use of the same or similar language items, from simple repetition, to reformulation, to new production and novel use" (p. 132). He added that shadowing is helpful in showing learners how to make adjustments and negotiations conducive to L2 acquisition. Specifically, shadowing may provide less able partners in conversation the means to get their interlocutors to adjust to their zones of proximal development (ZPDs) (Vygotsky, 1978, 1986). Interactive shadowing appears to be optimal venues for external (audible) verbalization, a necessary stage in the process of internalization of cultural tools, as proposed by Gal'perin (1969)'s approach to the development of mental potential.

In a recent study, Commander and M. de Guerrero (2016) used shadow-reading as a pedagogical technique aimed at fostering reading comprehension and retention in second (L2) or foreign language (FL) classrooms. The technique is an adaptation of "conversational shadowing," a procedure which requires listeners to repeat what their interlocutors say in an attempt to remember the content of the interaction while also practicing and learning a target language. In shadow-reading, learners are arranged in pairs in the roles of Readers and Shadowers. Readers read from a text while Shadowers listen and then try to reproduce the text in various forms: repeating completely or selectively, interjecting interactive comments, summarizing orally, and retelling in written form. The results unfolded that shadowing helped students attain reading comprehension with the socially-mediated approach. 


\section{Discussing the Second Research Question}

Data analysis conducted for the second research question revealed that TG learners' post-test scores were better than their pre-test and the differences were significant. Consequently, tracking technique can improve speaking fluency and thus the second null hypothesis was declined as well. When interacting with another person, individuals coordinate their behavior to take turns in the conversation. Dyadic interactions, and turn-taking behavior in particular, have received considerable attention in cognitive science, typified by several models of social interaction (Ho, Foulsham, \& Kingstone, 2015). These models have since been tested and quantified using both aggregated and temporally sensitive techniques. Cognitive scientists are beginning to include realistic interactions when investigating social attention in recognition of the fact that these introduce critical factors that are excluded during simulated social settings. Accordingly, the current study investigated the role of tracking in interactions, using modern tracking techniques and analyses, to determine the temporal dynamics inherent to natural interactions.

The most recent works in the quantification of social interactions have employed Cross Recurrence Quantification Analysis (CRQA). This method allows one to determine the percentage of co-occurring events in two-time series, sampled across all possible time points (Webber \& Zbilut, 2005). In the earliest usage of CRQA in studying interaction behavior, speakers and listeners were asked to look at an image on a computer screen. Both participants were eye tracked as the speaker talked about the image, and a high cooccurrence between the gaze of the speakers and listeners was found, with the listeners lagging behind speakers by about 2 seconds (Richardson \& Dale, 2005). Emphasizing further the importance of this temporal analysis, stronger coupling between the gaze of both dyad members was discovered to lead to higher levels of listener comprehension. In a later study, the gaze of speakers and listeners was again found to be tightly coupled, especially if both participants shared the same knowledge base (Richardson, Dale, \& Kirkham, 2007). These advances exposed a new domain of analysis methods for studying social interactions however, they have thus far been limited to interacting with a shared reference point (i.e., a computer screen). In order to study social attention in interactions, one would ideally study an interacting dyad in a face-to-face situation.

\section{Discussing the Third Research Question}

To test the third research hypothesis, the pre-test and post-test scores of the combined group were compared employing another paired-samples $t$ test. The results demonstrated that the combined effect of shadowing and tracking was also noticeable, and the speaking fluency of the participants improved. Therefore, the third hypothesis was also rejected.

The findings of the study are in line with the one conducted by Willardson (2014). He investigated the effectiveness of computer-enhanced shadowing and tracking pronunciation exercises in beginning level classes of foreign-language learning. The participants in his study were a group of high school students who were members of a fourth-year French class. The students participated in two types of exercises, in-class 
group work and computer-lab self-directed exercises, in which the students watched videos with subtitles while repeating what they heard. Collecting feedback by both qualitative and quantitative measures indicated the satisfaction of the students with the program. To the students, the videos were interesting and they appreciated the learning autonomy provided by the self-directed exercises. Improvement was assessed by comparing performance on pre-and post-tests measuring both free response and reading pronunciation. Significant improvements were observed in both categories, but the improvements in reading pronunciation were most striking.

\section{Discussing the Fourth Research Question}

To address this research hypothesis, one-way between groups ANOVA was conducted twice: once for the comparison of the oral fluency scores of the four groups at the outset of the study and a once again for comparing these four groups' oral fluency scores after the experiment was conducted. Following the application of ANOVA, Scheffe post hoc test was run to locate the exact place of differences. The results revealed that shadowing was significantly more effective than tracking. In addition, the combined effect of shadowing and tracking was significantly more effective than the effect of shadowing alone; this was also the case with tracking. That is, the combined effect of shadowing and tracking was found to be more effective than the effect of tracking alone. Moreover, these three experimental groups managed to have significantly higher mean scores than the control group. The results are consistent with the following studies: Azimi, and Ghanbari (2013) introduced the effect of conversational shadowing on enhancing the level of accuracy of EFL learners during their oral performance. Zakeri (2014) discovered that there is a link between shadowing and the fluency of EFL learners' oral performance. Shiota (2012) investigated that how shadowing can contribute to the field of language learning by examining one English class where students practice shadowing. Bovee and Stewart (2008) investigated the effects of shadowing on the English pronunciation of Japanese university students at three different proficiency levels.

\section{CONCLUSION}

It has always been the desire of researchers and teachers to develop more effective teaching techniques to help improve students' speaking skills. The results of this study indicated that shadowing and tracking are suitable for regular EFL classrooms, where the emphasis is on speaking fluency development. This study also demonstrated how theoretically-effective teaching techniques, shadowing and tracking, can be used more practically, building a bridge between theory and practice. Another important finding of the research was the positive combined impact of shadowing and tracking on speaking fluency of EFL learners. It appears that shadowing has not been very much popular in Iran and it is hoped that similar kinds of shadowing research will be conducted to develop similar learning procedures assisting greater numbers of students to increase their foreign-language skills. 


\section{REFERENCES}

Azimi Amoli, F. \& Ghanbari, F. (2013). The effect of conversational shadowing on enhancing Iranian EFL learners' oral performance based on accuracy. Journal of Advances in English Language Teaching, 1(1), 1-12. http://europeanscience.com/jaelt/article/view/75/pdf

Beebe, H.; Pearson, H; \& Koch, M.E. (1984). The Helen Beebe Speech and Hearing Center. In D. Ling (ed.), Early intervention for hearing-impaired children: Oral options (pp. 15-63), San Diego: College Hill Press.

Bovee, N. \& Stewart, J. (2009). The utility of shadowing. JALT 2008 Conference Proceedings. Tokyo: JALT.

Brown, G. \& Yule, G. (1983). Teaching the spoken language. Cambridge, Cambridge University Press.

Chaney, A. L. \& Burk, T. L. (1998). Teaching oral communication in grades K-8. Allyn and Bacon, Order Processing, PO Box 11071, Des Moines, IA 50336-1071.

De Filippo, C. \& Scott, B. (1978). A method for training and evaluating the reception of ongoing speech. Journal of the Acoustical Society of American, 63, 1186-1192.

Efrizal, D. (2012). Improving students' speaking through communicative language teaching method at Mts Ja-alhaq, Sentot Ali Basa Islamic boarding school of Bengkulu, Indonesia. International Journal of Humanities and Social Science, 2(20), 127-134.

Ellis, R. (1994). The Study of Second Language Acquisition. Oxford, UK: Oxford University Press.

Gal'prin, P. Ya. (1969). Stages in the development of mental acts. In A Handbook of Contemporary Soviet Psychology, ed. M. Cole \& I. Maltzman, pp. 249-273, New York, NY: Basic Books.

Housen, A. \& Kuiken, F. (2009). Complexity, accuracy and fluency in second language acquisition. Applied Linguistics, 30(4), 461-473. DOI: 10.1093/applin/amp048

Hunter, J. (2011). Small talk: Developing fluency, accuracy and complexity in speaking. ELT Journal, 66(1), 30-41. Doi.org/10.1093/elt/ccq093

Kalanzadeh, G.A.; Mirchenari, N.A; \& Bakhtiarvand, M. (2013). Perceived problems in using communicative language teaching (CLT) by EFL Iranian teachers. The International Journal of Language Learning and Applied Linguistics World, 2(3), 5-16.

Kasap, B. (2005). The effectiveness of task-based instruction in the improvement of learners' speaking skills. Maters' thesis, Bilkent, Ankara.

Mochizuki, M. (2006). Exploring the application of shadowing to Japanese education. Shicho kaku kyoiku [Audio-Visual Education] 6, 37-53. 
Murphy, T. (2001). Exploring conversational shadowing. Language Teaching Research, 5, 128-155. Doi.org/10.1177/136216880100500203

Rahimy, R. \& Safapour, S. (2012). The effect of using role-play on Iranian EFL learners' speaking ability. Asian Journal of Social Sciences \& Humanities, 1(3), 150159. http://www.ajssh.leena-luna.co.jp/AJSSHPDFs/Vol.1(3)/AJSSH2012(1.3-06).pdf

Richardson, D. C., \& Dale, R. (2005). Looking to understand: The coupling between speakers' and listeners' eye movements and its relationship to discourse comprehension. Cognitive science, 29(6), 1045-1060.

Richardson, D. C.; Dale, R.; \& Kirkham, N. Z. (2007). The art of conversation is coordination. Psychological Science, 18(5), 407-413. Doi.org/10.1111/j.14679280.2007.01914.x

Ricketts, K.G. \& Keith, K. (2013). Speaking for Success. University of Kentucky, College of Agriculture.

Sabzevari, A. (2012). Simultaneous effects of pre-task and on-line planning on complexity, accuracy, and fluency in L2 oral production of Iranian EFL learners. Science Series Data Report, 4(5), 86-101.

Shiota, K. (2012). The effectiveness of shadowing on students' psychology in language learning. Journal of Accents Asia, 5(1), 71-83. http://www.issues.accentsasia.org/issues/5-1/shiota.pdf

Skehan, P. (2003). Tasked-Based Instructions. Cambridge: Cambridge University Press.

Tamai, K. (2005a). An Introduction to Shadowing. Tokyo: Cosmo Pier Publishing.

Tamai, K. (2005b). References on the Effects of Using Shadowing as a Method of Teaching Listening. Tokyo: Kazama Shobo.

Tanaka, M. (2002). Modern interpreting: Where English education and interpreter training intersect. Tsuyaku-Honyaku Journal, 1. Retrieved from http://wwwsoc.nii.ac.jp/jais/html/tu_hon_journal/html/09_tanaka.html

Vygotsky, L. (1978). Mind in Society: The Development of Higher Psychological Processes. Cambridge, MA: Harvard University Press.

Webber C.L. \& Zbilut, J.P. (2005). Recurrence quantification analysis of nonlinear dynamical systems. In M.A. Riley and G.C. Van Order (ed.), Tutorials contempt: Nonlinear methods behavior (pp. 26-94), Sci. Web B.

Willardson, D. (2014). The effectiveness of computer-enhanced shadowing and tracking pronunciation exercises for intermediate level foreign language learners. Master's thesis, Brigham Young University, Provo, Utah, US.

Yuan, F. \& Ellis, R. (2003). The effects of pre-task planning and on-line planning on fluency, complexity and accuracy in second language monological oral production. Applied Linguistics, 24(1), 1-27. Doi.org/10.1093/applin/24.1.1 
Zakeri, E. (2014). Post method era: Amalgamation of methods: A real example. International Journal of Language Learning and Applied Linguistics World, 5(2), 523529. 